\title{
Tailoring the morphology and melting points of segmented thermoplastic polyurethanes by self-nucleation
}

Borja Fernández-d'Arlas, Jens Balko, R. Peter Baumann, Elmar Pöselt, Raphael Dabbous, Berend Eling, Thomas Thurn-Albrecht, Alejandro J. Müller

Index

\begin{tabular}{clc}
\hline Figure & \multicolumn{1}{c}{ Specification } & Pages \\
\hline Fig. S1. & $\begin{array}{l}\text { Self-nucleation experiments. Cooling and subsequent heating DSC } \\
\text { traces }\end{array}$ & $2-4$ \\
Fig. S2 & $\begin{array}{l}\text { Spherulitic texture of a "standard" morphology as observed by } \\
\text { PLOM. }\end{array}$ & 5 \\
Fig. S3 & $\begin{array}{l}\text { Impact of self-nucleation/crystallization on TPUs morphology as } \\
\text { studied by PLOM. }\end{array}$ & $6-9$ \\
Fig. S4 & $\begin{array}{l}\text { Domain borders as extracted from DSC self-nucleation analysis. } \\
\text { Fig. S5 }\end{array}$ & $\begin{array}{l}\text { Impact of cooling rate on self-nucleated samples at different } \\
\text { domains ranges. }\end{array}$ \\
Fig. S6 & $\begin{array}{l}\text { In-situ SAXS curves during heating } \\
\text { Int }\end{array}$ & 10 \\
\hline
\end{tabular}


Figure S1. Self-nucleation experiments. Cooling and subsequent heating DSC traces

\section{PUest33}

Cooling scans from indicated $T_{s}$ values

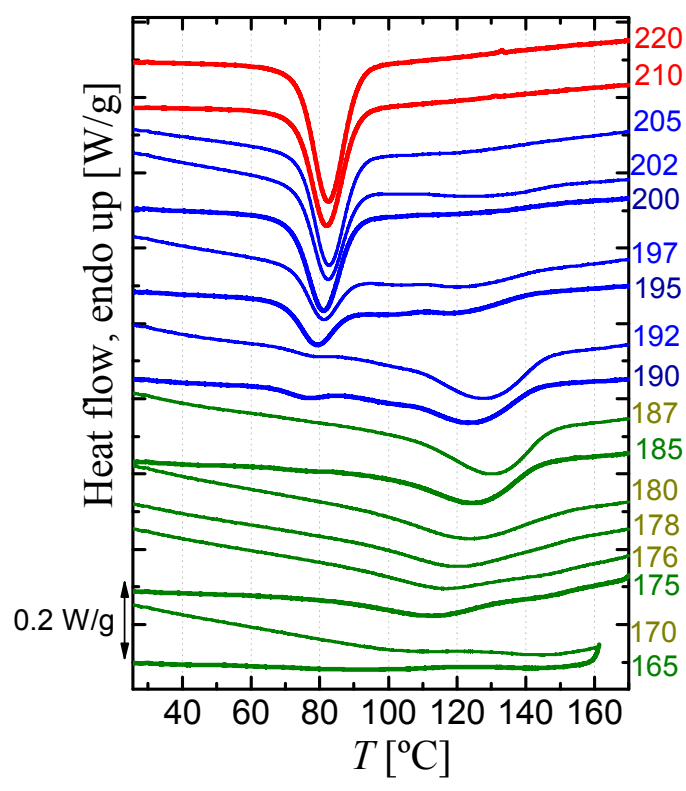

Subsequent heating scans

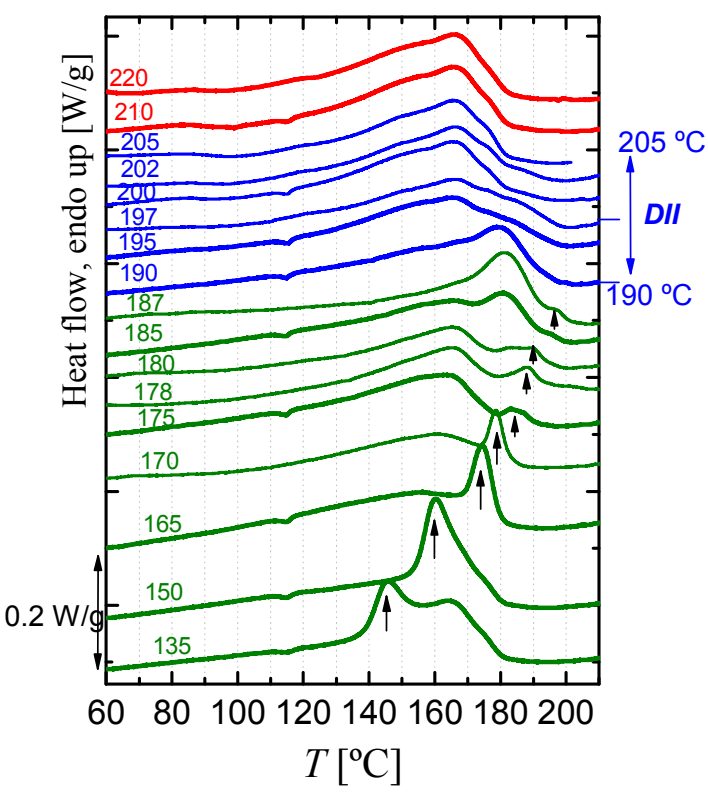




\section{PUeth30}

Cooling scans from indicated $T_{s}$ values:

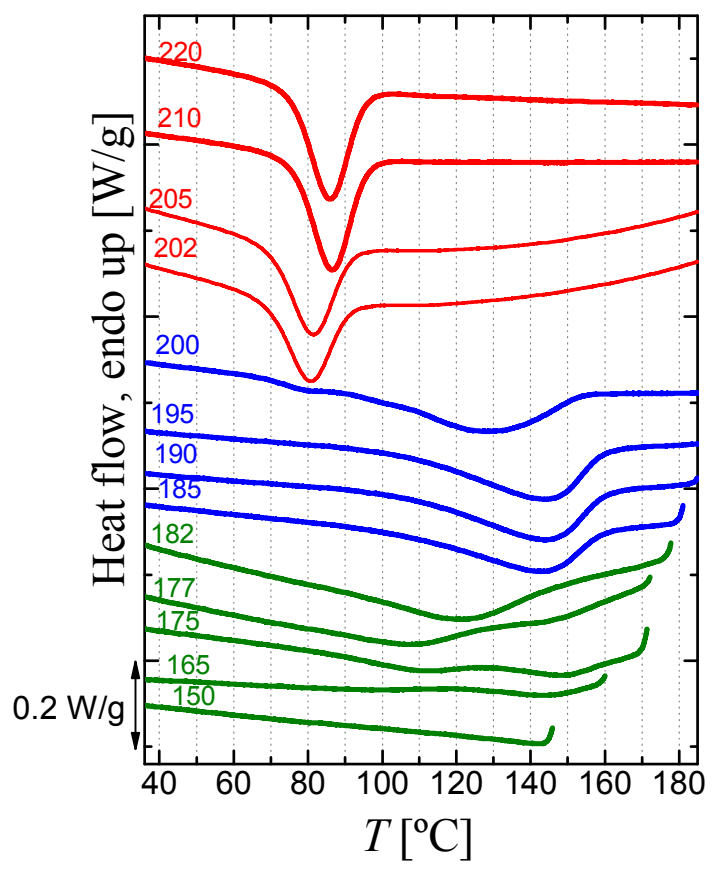

Subsequent heating scans:

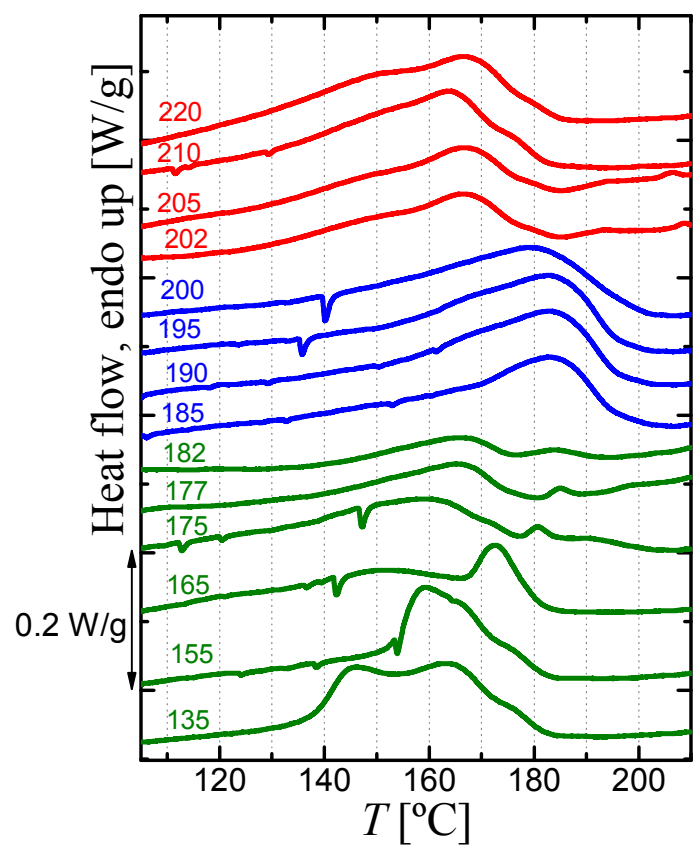




\section{PUeth43}

Cooling scans from inicated $T_{s}$ values:

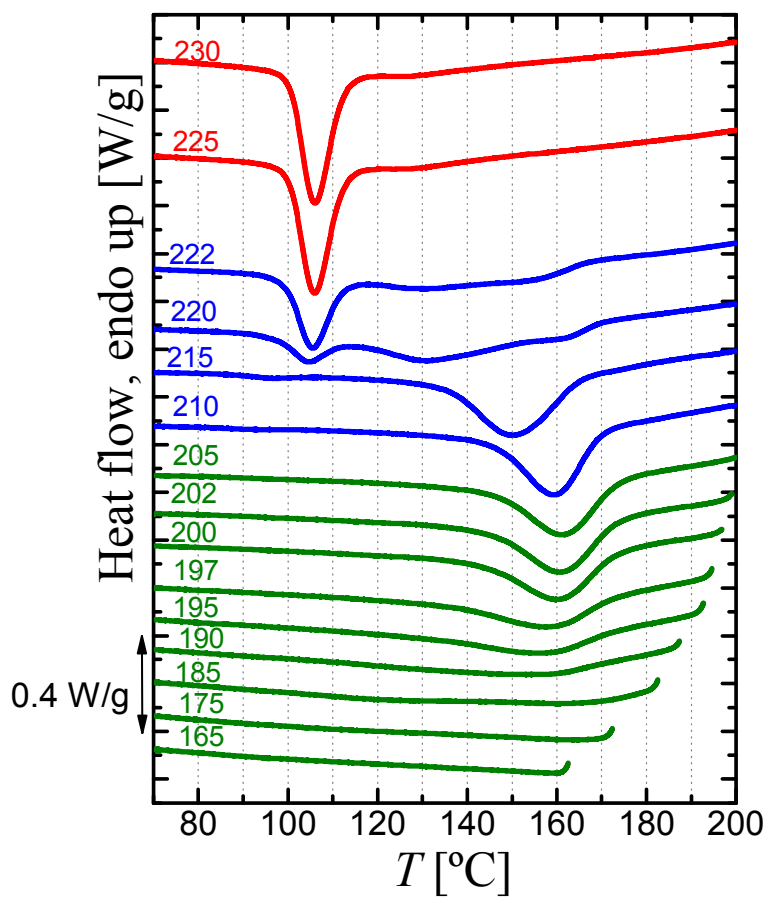

Subsequent heating scans:

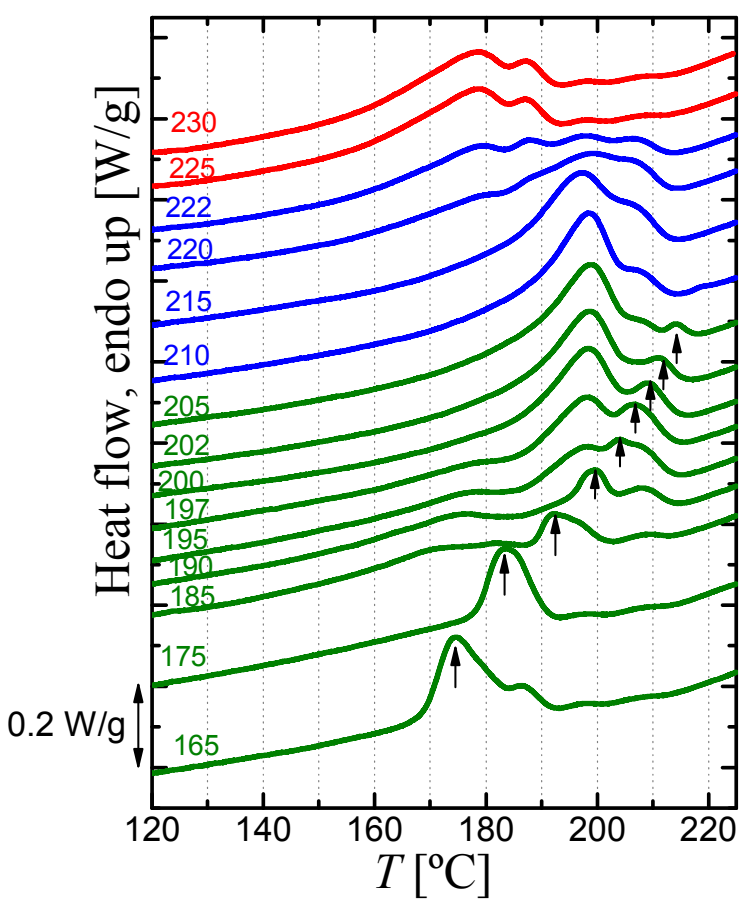


Figure S2. Spherulitic texture of a "standard" morphology as observed by PLOM.
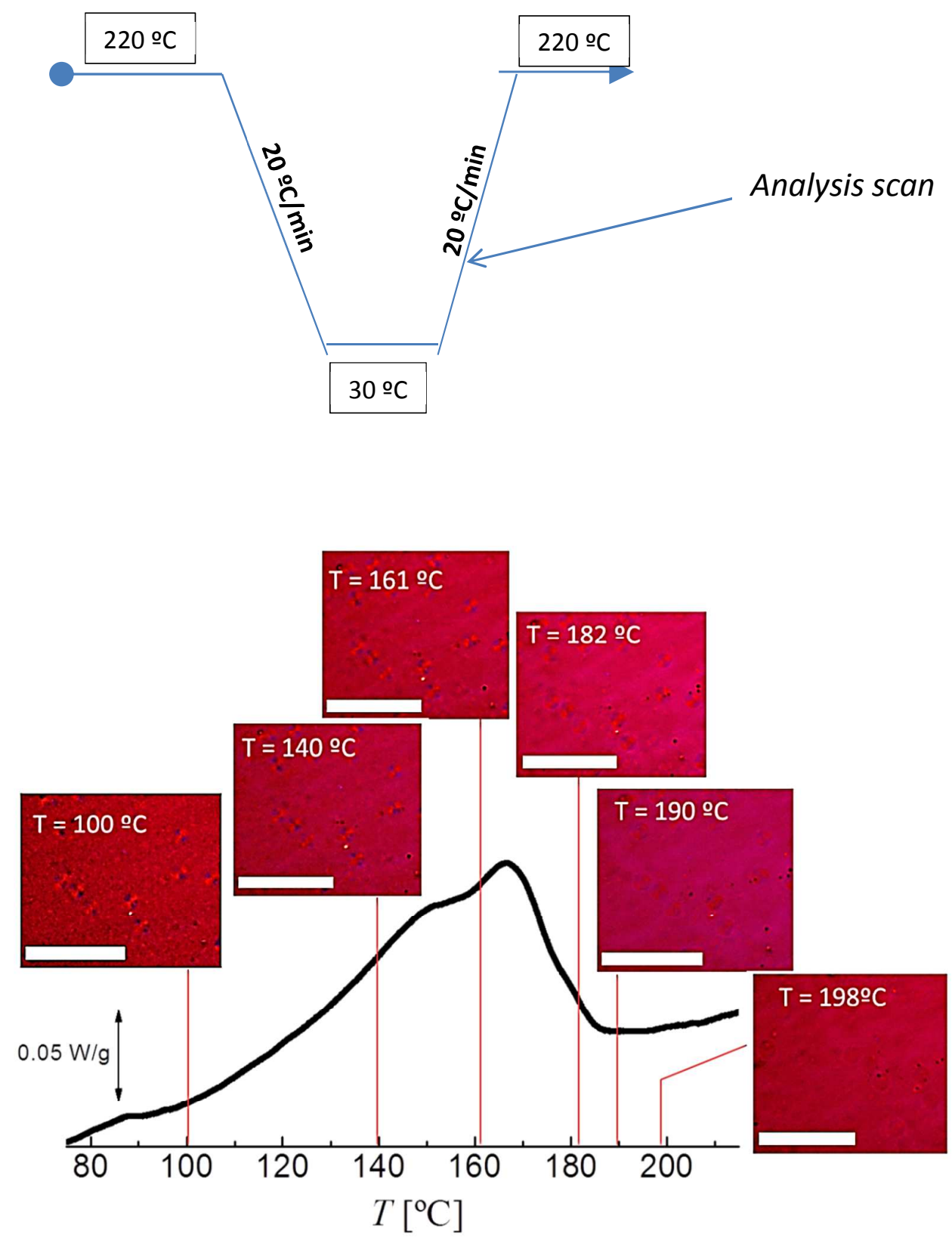

Figure S2. a) Thermal program for the morphological analysis shown in (b). b) DSC curve along the polarized light optical micrographs at different temperatures of PUeth30. The DSC curve was recorded at $20^{\circ} \mathrm{C} \cdot \mathrm{min}^{-1}$ while the images were acquired during a heating program of $10^{\circ} \mathrm{C} \cdot \mathrm{min}^{-1}$. Scale bars are of $88 \square \mathrm{m}$. 
Figure S3. Impact of self-nucleation/crystallization on TPUs morphology as studied by PLOM.

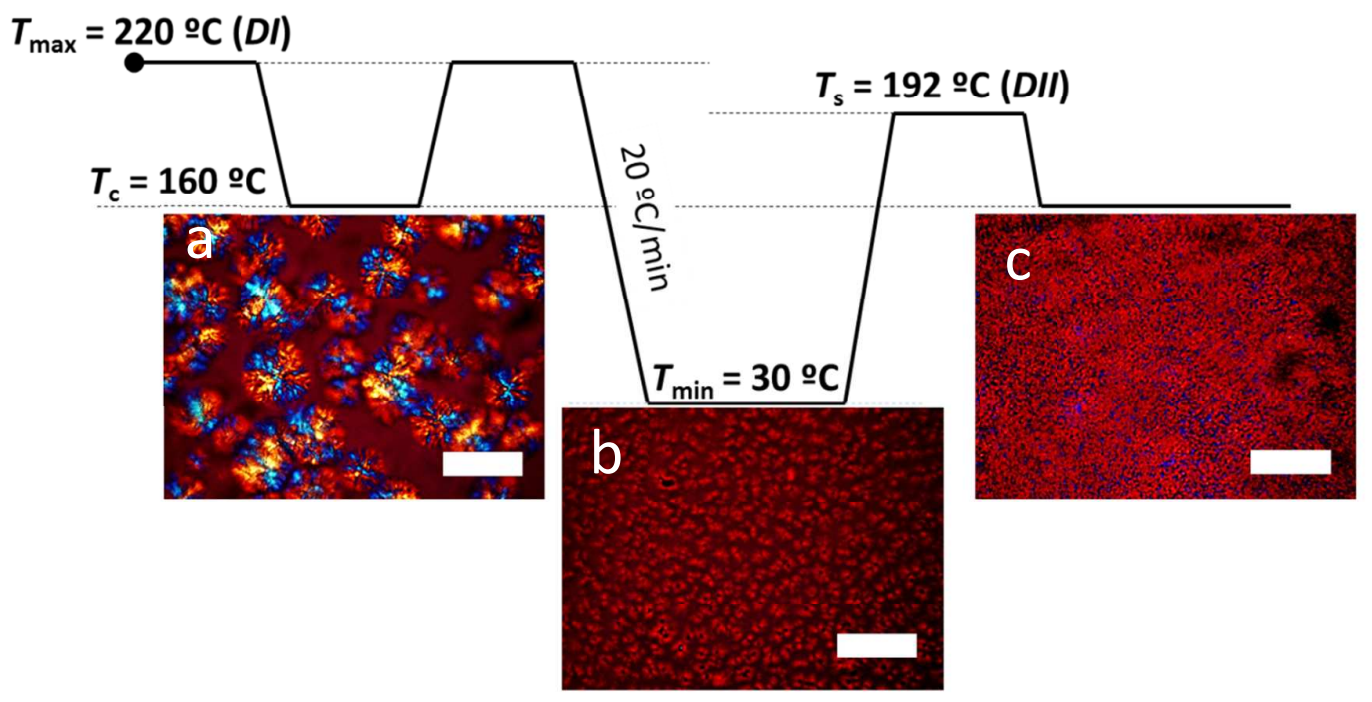

Figure S3a. Influence of different thermal treatments onto the morphology of PUest33. a)

Spherulites obtained after 50 min crystallization at $160^{\circ} \mathrm{C}$ after cooling from $D I$. b) Morphology obtained after direct cooling from $D I$ at $20^{\circ} \mathrm{C} \cdot \mathrm{min}^{-1}$. C) High nucleation density exhibited after 5 min crystallization at $160^{\circ} \mathrm{C}$ after cooling from $D I I\left(T_{\mathrm{s}}=192^{\circ} \mathrm{C}\right)$. Scale bars are of $88 \square \mathrm{m}$. 


\section{Figure S3b}

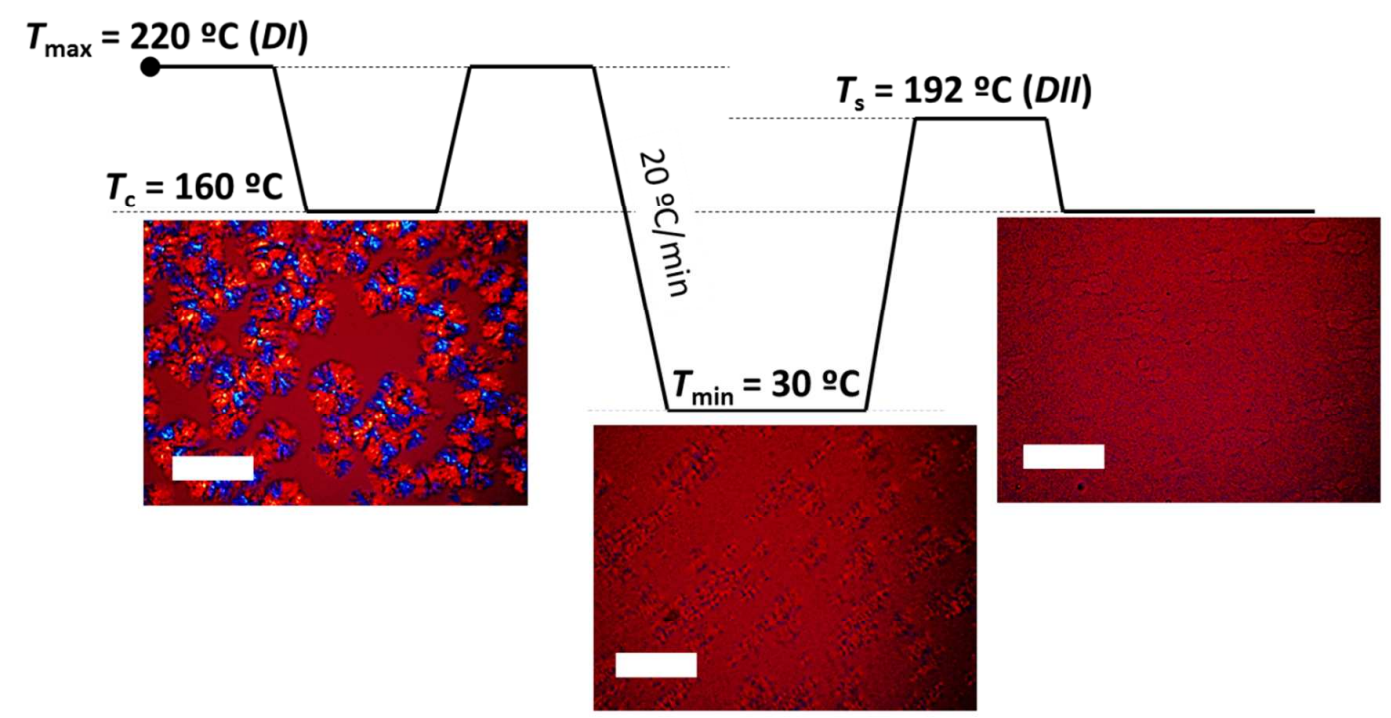

Figure S3b. Influence of different thermal treatments onto the morphology of PUeth30. a) Spherulites obtained after 190 min crystallization at $160^{\circ} \mathrm{C}$ after cooling from $D I$. b) Morphology obtained after direct cooling from $D I$ at $20^{\circ} \mathrm{C} \cdot \mathrm{min}^{-1}$. C) High nucleation density exhibited after $5 \mathrm{~min}$ crystallization at $160^{\circ} \mathrm{C}$ after cooling from $\mathrm{DII}\left(T_{\mathrm{s}}=192^{\circ} \mathrm{C}\right)$. Scale bars are of $88 \square \mathrm{m}$. 


\section{Figure S3c}

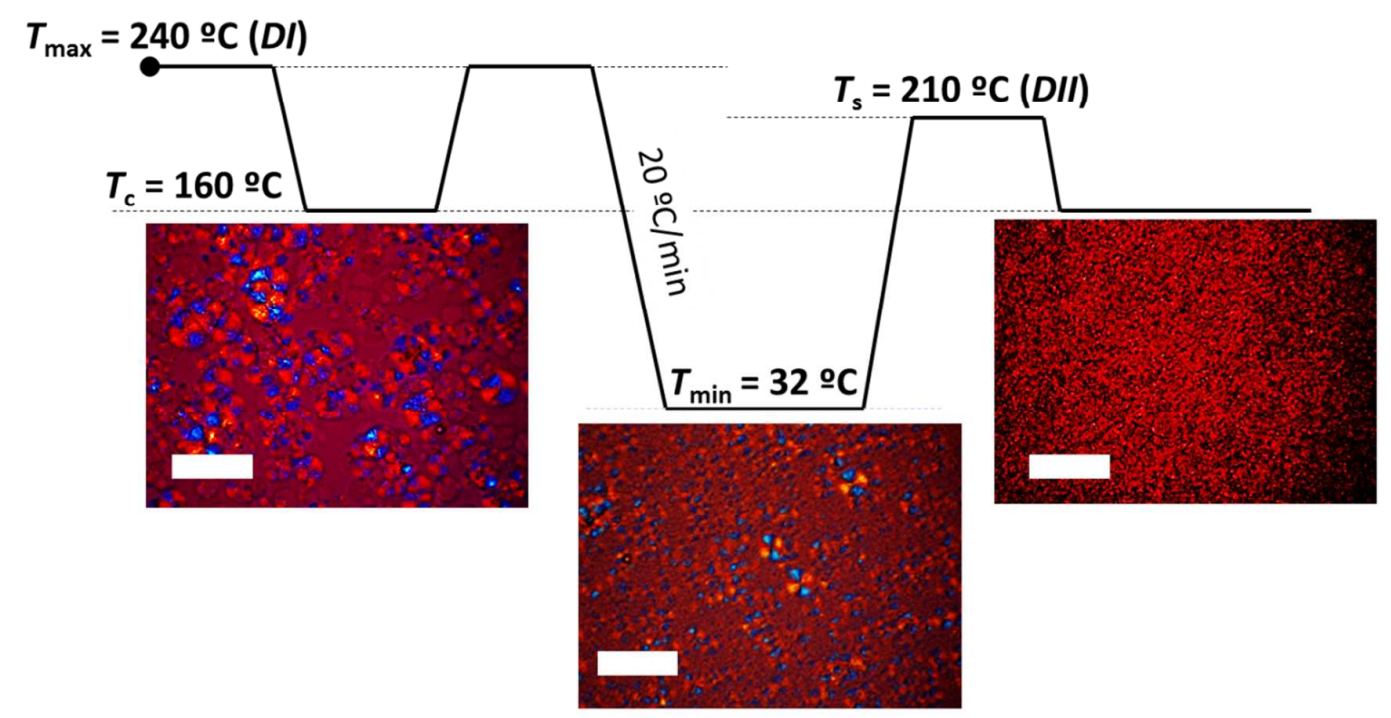

Figure S3c. Influence of different thermal treatments onto the morphology of PUeth43. a) Spherulites obtained after $5 \mathrm{~min}$ crystallization at $160^{\circ} \mathrm{C}$ after cooling from $D I$. b) Morphology obtained after direct cooling from $D I$ at $20^{\circ} \mathrm{C} \cdot \mathrm{min}^{-1}$. C) High nucleation density exhibited after 5 min crystallization at $160^{\circ} \mathrm{C}$ after cooling from $D I I\left(T_{\mathrm{s}}=210{ }^{\circ} \mathrm{C}\right)$. Scale bars are of $88 \square \mathrm{m}$. 


\section{Figure S3d}

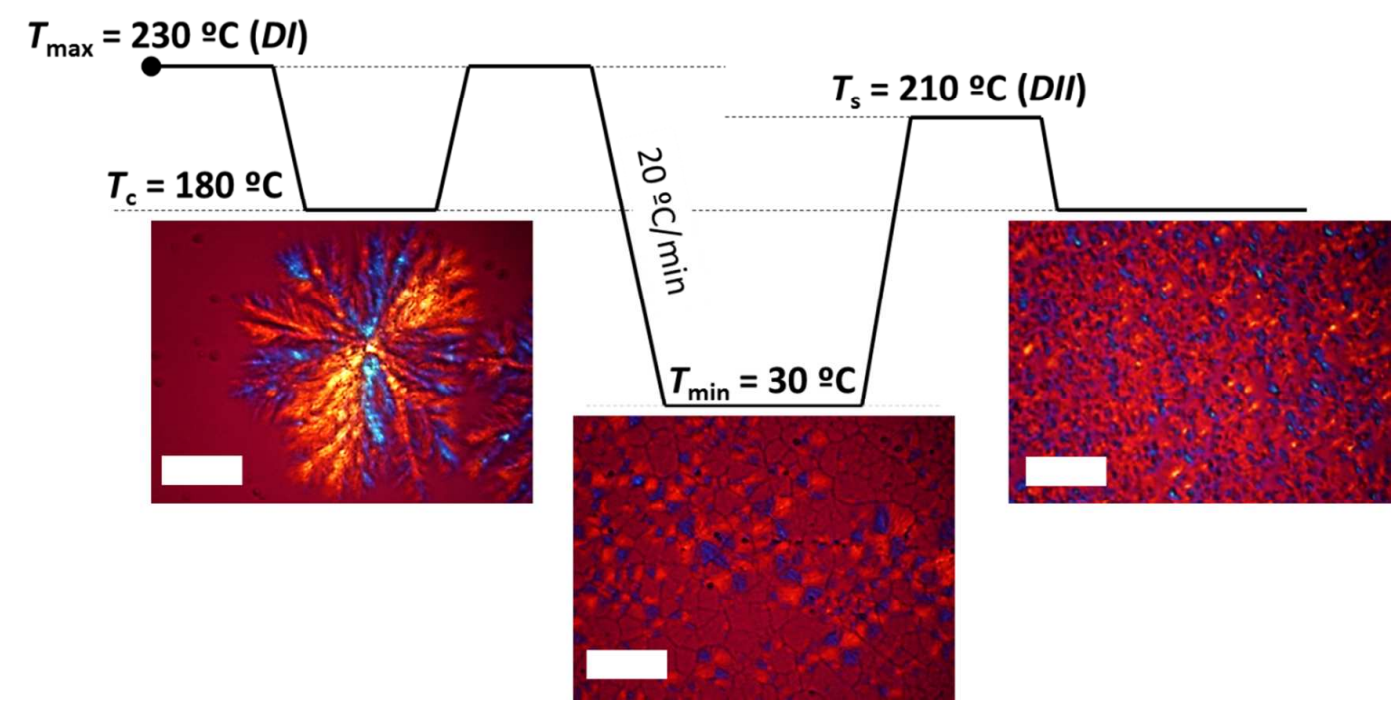

Figure S3d. Influence of different thermal treatments onto the morphology of PUeth43. a) Spherulites obtained after 53 min crystallization at $180^{\circ} \mathrm{C}$ after cooling from $D I$. b) Morphology obtained after direct cooling from $D I$ at $20^{\circ} \mathrm{C} \cdot \mathrm{min}^{-1}$. C) High nucleation density exhibited after 17 min crystallization at $180^{\circ} \mathrm{C}$ after cooling from $D I I\left(T_{\mathrm{s}}=210^{\circ} \mathrm{C}\right)$. Scale bars are of $88 \square \mathrm{m}$. 
Figure S4. Domain borders as extracted from DSC self-nucleation analysis.

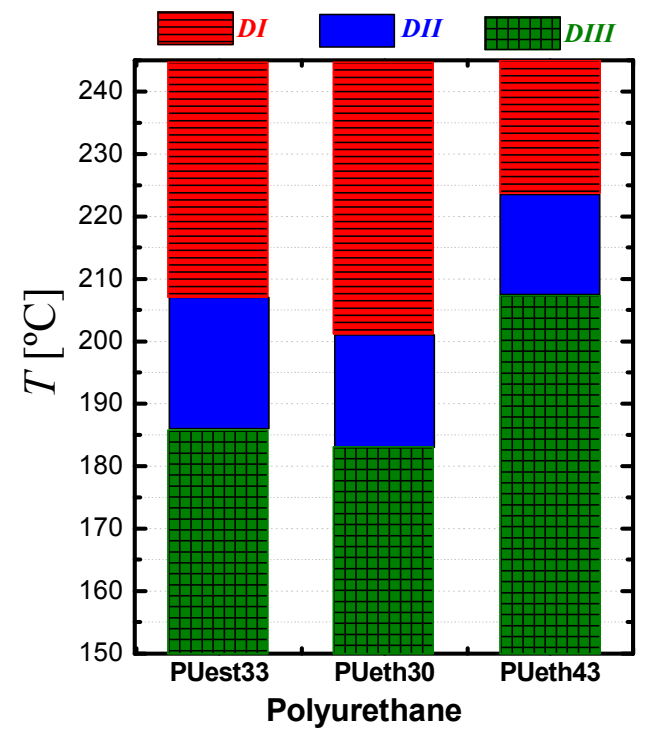

Figure S4. Temperature domain ranges shorted according to their SN behavior for each of the studied TPUs and plotted in the same temperature scale. 
Figure S5. Impact of cooling rate on self-nucleated samples at different domains ranges.
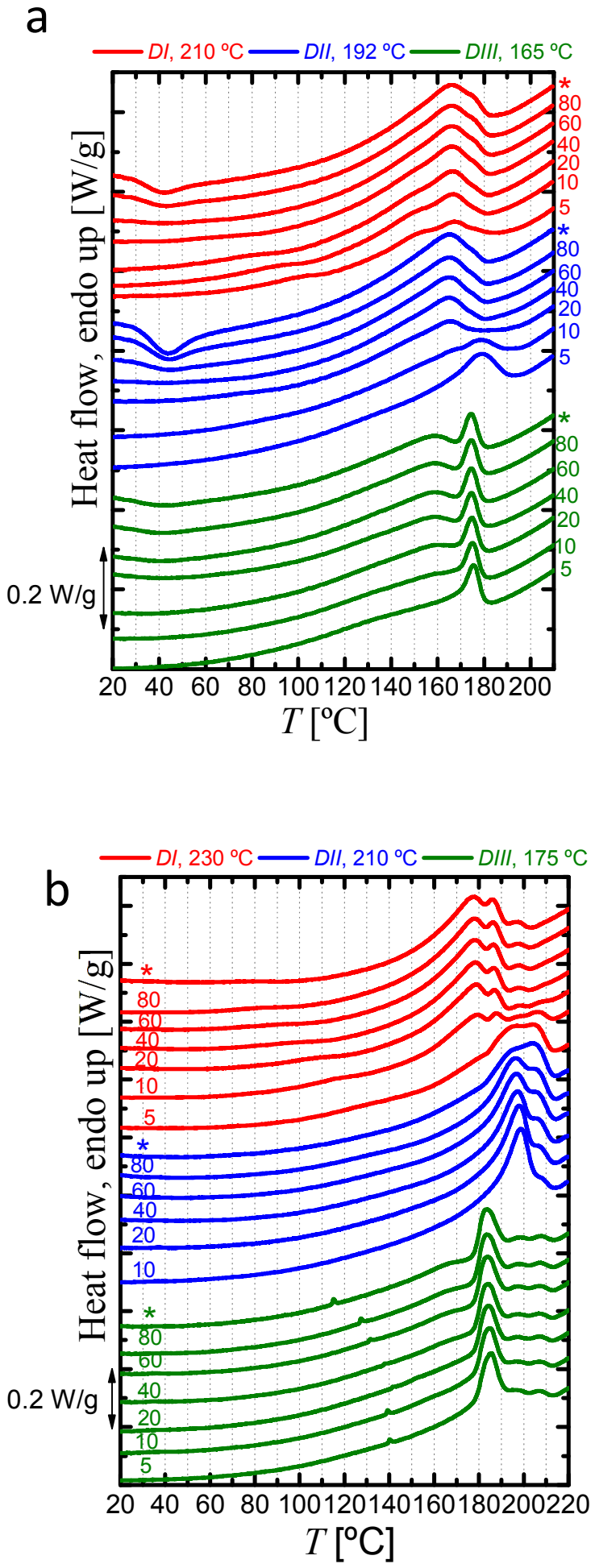

Figure S5. Influence of cooling rate on morphology. Subsequent heating scans after cooling at the indicated heating rates $\left({ }^{\circ} \mathrm{C} \cdot \mathrm{min}^{-1}\right)$ from different temperatures at $D I, D I I$ and $D I I I$ of a) PUest33, and b) PUeth43. *Indicates a ballistic cooling rate of $\approx 160{ }^{\circ} \mathrm{C} \cdot \mathrm{min}^{-1}$. 


\section{Figure S6: In-situ SAXS curves during heating}

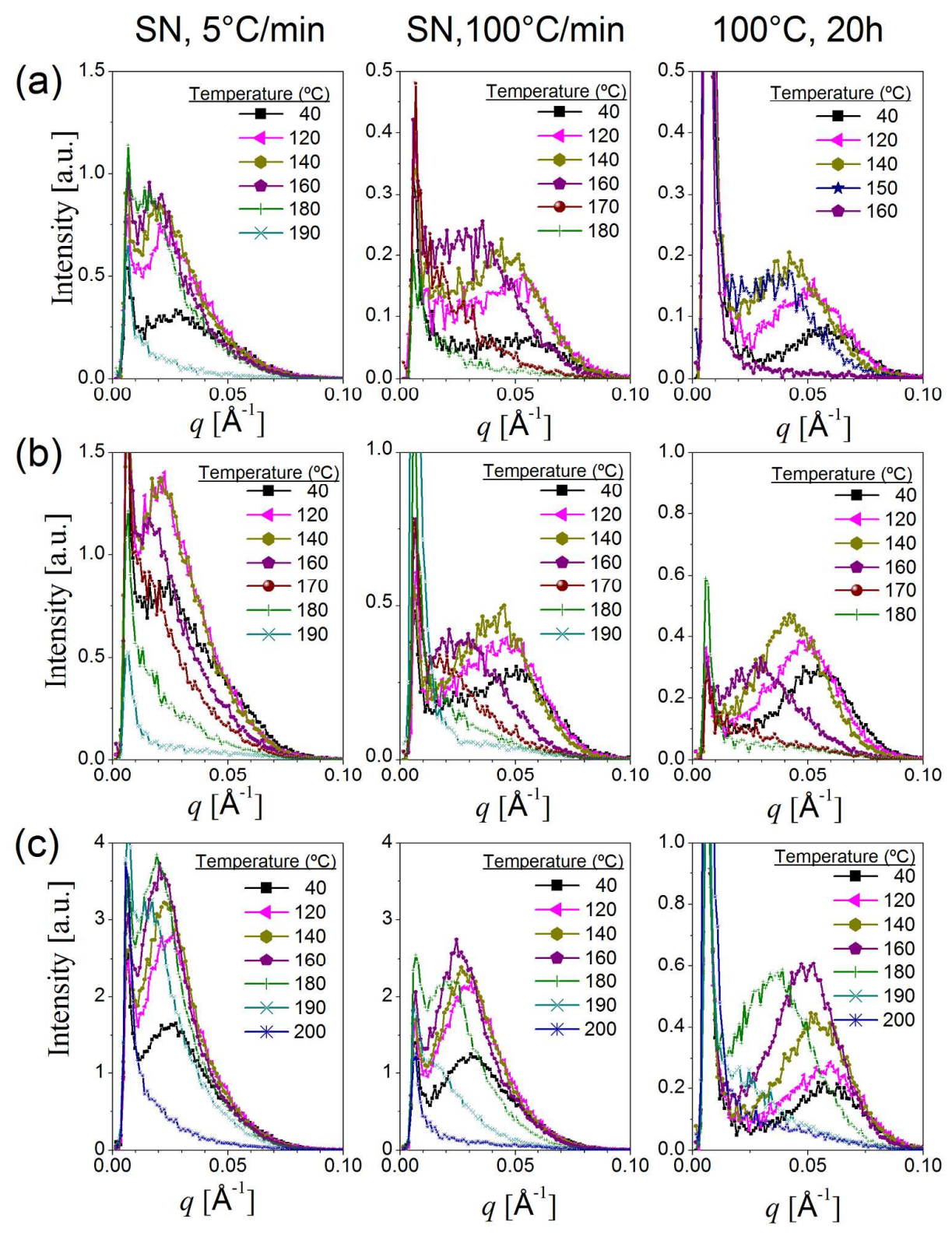

Figure S6. In-situ SAXS curves during heating from $T=40{ }^{\circ} \mathrm{C}$ to the molten state for (a) PUest33, (b) PUeth30 and (c) PUeth43 being cooled with $5{ }^{\circ} \mathrm{C} \cdot \mathrm{min}^{-1}$ after SN (first column), cooled with $100{ }^{\circ} \mathrm{C} \cdot \mathrm{min}^{-1}$ after SN (second column) or annealed at $100{ }^{\circ} \mathrm{C}$ for $20 \mathrm{~h}$ after injection molding (third column). For clarity only selected data are presented. The $T_{s}$ temperature employed for SN was $192{ }^{\circ} \mathrm{C}$ (for PUest33 and PUeth30) and $210^{\circ} \mathrm{C}$ for PUeth 43. 